\title{
Memórias do nazismo e da guerra em duas gerações de descendentes de alemães repatriados para o Brasil $^{1}$
}

\section{Memories of nazism and war in two generations of Germans's descendants repatriated to Brazil}

\section{Méri Frotscher ${ }^{2}$}

Resumo: $\mathrm{O}$ artigo explora histórias de vida de dois entrevistados, mãe e filho que, juntos, vivenciaram a emigração para a Alemanha, em 1938, no contexto da repressão ao partido nazista no Sul do Brasil, a Segunda Guerra Mundial na Alemanha - bombardeios, evacuação, fuga da zona de ocupação soviética - e a repatriação ao Brasil, em 1946/7. Ambos, contudo, apreendem tais eventos e o envolvimento do marido e pai, respectivamente, com o nacionalsocialismo de formas distintas e, às vezes, contraditórias. Com base neste estudo de caso, discutimos a problemática da reconstrução da memória em duas gerações, por meio da noção de "memória comunicativa", formulada por Jan
Abstract: The article explores life stories of two interviewees, mother and son, who together experienced the emigration to Germany in 1938 in the context of the repression of the Nazi Party in South Brazil, the Second World War II in Germanybombing, evacuation, fligth of the Soviet zone - and the repatriation to Brazil in 1946/47. However, both apprehend these events and the participation of the husband and father, respectively, in the national socialism in different ways and sometimes contradictory. Through this case study, we discuss the problem of memory reconstruction in two generations, based on the notion of "communicative memory" formulated by Jan Assmann and developed by the social

\footnotetext{
${ }^{1}$ Este artigo é a versão em português modificada e atualizada de artigo publicado em espanhol em periódico impresso na Argentina: FROTSCHER, Méri. Memorias de guerra y del nazismo em dos generaciones de descendientes de alemanes repatriados a Brasil. Historia, Voces y Memoria, Buenos Aires, n. 3, p. 49-78, 2011a.

${ }^{2}$ Doutora em História Cultural pela Universidade Federal de Santa Catarina (UFSC), com pós-doutorado pelo Instituto Latino-Americano da Universidade Livre de Berlim. Professora associada da Universidade Estadual do Oeste do Paraná (UNIOESTE). Email: merikramer@ hotmail.com
} 
Assmann e desenvolvida pelo psicólogo social Harald Welzer e sua equipe em seu estudo sobre o nacional-socialismo e o holocausto na memória familiar.

Palavras-chave: história oral; memória; geração; nazismo; Segunda Guerra Mundial psychologist Harald Welzer and his team in their study about the national-socialism and the holocaust in the familiar memory.

Keywords: oral history; memory; generation; nazism; World War II

Após o final da Segunda Guerra Mundial, milhões de refugiados e "deslocados de guerra" (displaced persons) que se encontravam na Alemanha foram enviados de volta para seus países de origem. Entre eles se encontravam cidadãos brasileiros, que foram encaminhados para o Brasil pela Missão Militar Brasileira instalada em Berlim, muitos dos quais acompanhados de familiares de cidadania alemã, por meio de uma ação então chamada de "repatriação". ${ }^{3}$ A maioria desses "repatriados", diferente dos "deslocados de guerra" vítimas do nacional-socialismo, era de descendente de alemães com experiências de migração entre Brasil e Alemanha, tendo, eles próprios ou seus pais, se dirigido ao Brasil durante a República de Weimar (1919-1933) e voltado para a Alemanha entre 1938 e 1939.

Este artigo se baseia em entrevistas de histórias de vida com os próprios migrantes/retornados/ "repatriados". Abordamos o caso específico de uma das famílias, com o propósito de discutir, a partir de entrevistas de história de vida com a mãe e o filho de um membro do partido nazista no Brasil e na Alemanha, a construção de diferentes memórias sobre os mesmos eventos, sobretudo no que se refere às experiências de guerra e ao nazismo. Menos que reconstituir fatos, visamos apreender de que forma os entrevistados narram os processos migratórios, as vivências de guerra, como

${ }^{3}$ Sobre isto ver: FROTSCHER, Méri. De alemães no exterior a brasileiros? A repatriação de cidadãos brasileiros da Alemanha ocupada (1946-1949). História Unisinos, v. 17, p. 81-96, 2013a. 
"constroem e atribuem significados"4 a estes acontecimentos e como rememoram e lidam com o passado nacional-socialista. Antes disso trazemos ao texto alguns elementos sobre as migrações múltiplas entre Brasil e Alemanha na primeira metade do século XX, vividas por essas famílias.

\section{Idas e vindas: a emigração ao Brasil, a "remigração" à Alemanha e a "repatriação" ao Brasil}

Após a Primeira Guerra Mundial, milhares de alemães haviam se dirigido para as Américas e, dos países latino-americanos, o Brasil foi o que, entre 1919 e 1932, mais recebeu imigrantes alemães, cerca de 58.500 pessoas. ${ }^{5}$ Parte desses migrantes se instalou no Sul do Brasil, em regiões onde anteriormente já haviam se estabelecido "colônias" alemãs. Ali, diferenças entre esses alemães e outros já estabelecidos, assim como seus descendentes, se manifestaram, a começar pelo uso de expressões como Reichsdeutscher (cidadão alemão), Neudeutscher (alemão novo) ou Deutschländer (provindo da Alemanha), usadas para se identificar os novos imigrantes. Mais tarde, um pouco antes do início da Segunda Guerra Mundial, sobretudo entre 1938 e 1939, a propaganda e as expectativas em relação à "Nova Alemanha" sob o nacional-socialismo, assim como a repressão ao NSDAP e a nacionalização de estrangeiros no Brasil, entre outras razões, levaram uma parte - uma pequena parte, vale frisar - destes Auslandsdeutsche 6 ("alemães no exterior") que haviam chegado na primeira metade do século XX para o Brasil a retornar para a Alemanha. ${ }^{7}$

${ }^{4}$ PORTELLI, Alessandro. A Filosofia e os Fatos. Narração, interpretação e significado nas memórias e nas fontes orais. Tempo, Rio de Janeiro, v. 1, n. 2, p. 59-72, 1996.

${ }^{5}$ RINKE, Stefan. "Der letzte freie Kontinent". Deutsche Lateinamerikapolitik im Zeichen transnationaler Beziehungen. 1918-1933. Stuttgart: Akademischer Verlag, 1996, p. 294.

${ }^{6} \mathrm{O}$ termo Auslandsdeutschtum se referia a todos os alemães e descendentes que moravam no exterior e que não tinham a cidadania alemã. Eram considerados alemães por conta da descendência, da língua, costumes, tradições e traços culturais considerados alemães.

${ }^{7}$ Os seguintes artigos, escritos com base em "trajetórias de vida" de retornados, foram, até o momento publicados: FROTSCHER, Méri. Narrar a vida durante o III Reich. Interpretação de 'trajetórias de vida' escritas por 'retornados' à Alemanha a partir do Brasil. Naveg@merica, Murcia, v. 11, p. 1-18, 2013b; FROTSCHER, Méri. "Als Nationalsozialist tat ich jederzeit unter schwersten persönlichen Opfern 
Até o momento o tema do retorno para a Alemanha durante o regime nazista, a partir do Brasil, ainda não foi tema de investigação. Isso também vale para períodos anteriores da história das migrações entre Brasil e Alemanha, quando também houve fluxos de retorno. Também as migrações múltiplas entre os dois países têm sido pouco iluminadas pelas pesquisas. Durante o nazismo, o movimento de retorno de alemães foi representado e instrumentalizado pela propaganda nazista como um movimento Heim ins Reich (de volta para a pátria). Na historiografia alemã, esse movimento populacional específico se refere aos descendentes de alemães que foram deslocados para a Alemanha durante o regime nacionalsocialista de áreas no Leste Europeu que ficaram sobre a influência soviética após 1939, em razão do Pacto entre Hitler e Stalin. Nossa investigação se refere à remigração a partir do Brasil durante os anos 1930 em conexão com o retorno de parte destes mesmos alemães e descendentes para o Brasil depois da II Guerra Mundial. ${ }^{8}$ Muito embora aquela expressão nacional-socialista (Heim ins Reich) tenha sido mencionada por algumas das pessoas por nós entrevistadas, o seu retorno à Alemanha não fez parte daquela política oficial.

Sobretudo pessoas que vieram para o Brasil nos anos 1920 ou seus filhos remigraram para a Alemanha em fins dos anos 1930, com o objetivo de tomar parte das possibilidades de estudo e trabalho que a propaganda nazista acenava. ${ }^{9}$ Alguns deles retornaram/se dirigiram para servir no Reichsarbeitsdienst ${ }^{10}$ e ao Exército Alemão, como é o caso de um de nossos entrevistados. ${ }^{11}$ Ernst, morador de Joinville, embarcou em direção à Alemanha no início de 1939, juntamente com outros jovens, tendo metade dos custos da viagem subsidiados pelo governo alemão, para "servir a Hitler

meine Pflicht”. Autobiographische Erzählung eines Rückwanderers aus Brasilien im institutionellen Kontext.. Bios, Leverkusen, v. 26, p. 129-143, $2013 \mathrm{c}$.

${ }^{8}$ Objeto do projeto de pesquisa Memórias da guerra e do nazismo: a repatriação de cidadãos brasileiros da Alemanha após a II Guerra Mundial (Programa de Estágio Pós-Doutoral CAPES). Sobre o assunto ver FROTSCHER (2013a).

${ }^{9}$ Sobre isso ver FROTSCHER (2013a).

${ }^{10}$ Após junho de 1935, todo jovem alemão deveria prestar serviços, durante seis meses, para o Reichsarbeitsdienst, como preparação para o serviço militar. Esta era uma organização do aparato nacional-socialista que tomava parte do programa econômico e do sistema de educação nacional-socialista e que teve papel importante para a preparação da guerra.

${ }^{11}$ Projeto "Memórias da guerra e do nazismo: a repatriação de cidadãos brasileiros da Alemanha após a II Guerra Mundial" (Programa de Estágio Pós-Doutoral CAPES). 
como soldado", como ele rememora ironicamente. ${ }^{12}$ Durante alguns meses serviu para o Reichsarbeitsdienst, organização nacional-socialista para a qual todo jovem deveria prestar serviços, e, em setembro, surpreendido pelo início da guerra, tomou parte ativa dela como soldado, lutando em diversos fronts.

Filhos de alemães nascidos no Brasil, considerados brasileiros pela legislação brasileira, baseada no jus solis, e alemães pela legislação alemã, baseada no jus sanguinis, também combateram pela Alemanha. ${ }^{13}$ Ao final da II Guerra, os cidadãos brasileiros que estavam na Alemanha foram considerados displaced persons (deslocados de guerra) pelas Tropas Aliadas, ou seja, pessoas que ao final da guerra não se encontravam no seu país de origem e que não poderiam retornar ou migrar para outro país sem algum auxílio. Segundo estudo sobre o problema dos refugiados na Alemanha após a guerra, os "deslocados de guerra", em contraste com os refugiados alemães expulsos pelas tropas do Exército Vermelho, seriam aqueles de "origem não alemã", em geral vítimas da perseguição nazista. ${ }^{14}$ Era o caso, principalmente, dos Zwangsarbeiter (trabalhadores forçados) ou Zwangsverschleppte (trabalhadores sequestrados de seus lugares de origem e encaminhados ao Reich alemão durante o nazismo), a maioria do Leste Europeu. Este não era o caso dos cidadãos brasileiros "repatriados" - a quase totalidade de origem alemã e que havia se dirigido voluntariamente à Alemanha no final dos anos 30 - mas mesmo assim foram incluídos nas ações de repatriação. Para eles, voltar ao Brasil era uma oportunidade de escapar da carência de mantimentos e das difíceis condições de vida do pósguerra. Tanto nesse momento, como quando vieram do Brasil, anteriormente, muitos aproveitaram seus laços transnacionais em momentos de dificuldade e perigo para poder migrar/retornar.

12 Ernst Eders [pseudônimo]. Entrevista realizada em 03.10.2009. Entrevistadora: Méri Frotscher. As citações das entrevistas, feitas em língua alemã, foram traduzidas pela autora. Para ver mais detalhes sobre essa entrevista, ver FROTSCHER, Méri. Língua, memória e identidade. Considerações metodológicas sobre histórias de vida de migrantes bilíngues. História Oral, Rio de Janeiro, v. 1, p. 97-122, 2011 b.

13 Sobre isso ver FROTSCHER (2013b); OLIVEIRA, Dennison de. Os soldados brasileiros de Hitler. Curitiba, Editora Juruá Ltda, 2008 e o livro escrito pelo exmembro da Missão Militar Brasileira em Berlim: TAVARES, Aurélio de Lyra. Quatro anos na Alemanha ocupada. Rio de Janeiro, Biblioteca do Exército, 1951. 14 Betty Barton. The problem of 12 million German refugees in today's Germany. Philadelphia: American Friends Service Committee, 1949, p. 5. 
Por conta destas e outras questões, os termos "deslocados de guerra", "repatriação" e até mesmo "brasileiro" ou "alemão" devem ser vistos com cuidado e a partir dos significados atribuídos pelas fontes à época de sua utilização. Tanto a classificação feita pelos Aliados como as leis de cidadania brasileiras partiam da concepção de que a pátria era o local de nascimento destas pessoas, as quais, em razão disso, foram consideradas "deslocadas", não importassem os sentimentos que esses descendentes de alemães, considerados cidadãos brasileiros pelo Estado brasileiro, alimentavam em relação ao Brasil e à Alemanha. Como "deslocados de guerra" deveriam ser, conforme a política das autoridades militares da Alemanha ocupada, enviados de volta ao Brasil. Para a compreensão disso, deve-se considerar o grave problema da superpopulação, a falta de moradias e as sérias dificuldades de abastecimento na Alemanha. Estes problemas foram agravados pela presença dos milhões de "deslocados de guerra" e de alemães expulsos do Leste Europeu. No final da guerra, os deslocados de guerra perfaziam um total de 9 a 11 milhões de pessoas. ${ }^{15} \mathrm{~A}$ maioria deles foi enviada de volta aos seus países de origem logo depois da guerra.

Os brasileiros foram repatriados mais tarde, entre fins de 1946 e fins de 1949. Além dos brasileiros, seus parentes de cidadania alemã, quando submetidos ao processo de "desnazificação" e liberados pelas autoridades das zonas de ocupação, puderam acompanhá-los. $\mathrm{O}$ processo de "desnazificação" correspondeu ao processo de limpeza política (politischer Säuberungsprozess) da sociedade alemã, o qual deveria atingir, conforme decidido na Conferência de Potsdam, em 1945, o círculo de pessoas que participaram ativamente do governo nacional-socialista, isto é, mais do que nominalmente membros do NSDAP. ${ }^{16} \mathrm{Na}$ zona norte-americana, a mais burocrática neste processo, formulários com 131 questões sobre detalhes do passado profissional e político deveriam ser preenchidos e analisados pelas autoridades. ${ }^{17} \mathrm{O}$ processo de "desnazificação" foi muito lento e, além disso, incompleto, problemático e até hoje alvo de críticas, a começar pelo termo. ${ }^{18}$ Em 1948, foi dado fim ao processo de "desnazificação" na zona

15 PLATO, Alexander von; LEH, Almut. "Ein unglaublicher Frühling". Erfahrene Geschichte im Nachkriegsdeutschland. 1945-1948. Bonn: Bundeszentrale für politische Bildung, 1997, p. 19.

16 BENZ, Wolfgang. Entnazifizierung. In: (Ed.) Legenden, Lügen, Vorurteile. Ein Wörtgerbuch zur Zeitgeschichte. 7. Auflage. München: DTV, 1995, p.69.

${ }^{17}$ Idem, p. 70.

${ }^{18} \mathrm{Um}$ dos primeiros estudos a problematizar este processo foi o importante estudo de Lutz Niethammer sobre o processo de "desnazificação" na Baviera, publicado 
norte-americana, pois os interesses já eram outros. Neste momento, quando já era clara a polarização entre a zona soviética e as demais zonas de ocupação e se configurava a Guerra Fria, as autoridades ocidentais passaram a priorizar a reconstrução da Alemanha. ${ }^{19}$

A Missão Militar Brasileira enviada à Alemanha se incumbiu de efetuar a "repatriação" dos cidadãos brasileiros e de seus parentes alemães. De acordo com o Sub-Chefe da Missão Militar Brasileira em Berlim, Coronel Aurélio de Lyra Tavares, autor do livro Quatro anos na Alemanha ocupada, entre fevereiro de 1947 e dezembro de 1949, 5.885 pessoas foram transportadas, em 11 levas, pelos navios Santarém e Duque de Caxias. ${ }^{20}$ Dentre estas pessoas, cerca da metade era constituída por cidadãos brasileiros e a outra metade, de familiares alemães. ${ }^{21}$

As experiências migratórias dessas pessoas entre Brasil e Alemanha extrapolam os limites de uma historiografia nacional e revelam a complexidade e a multiplicidade de relações que os sujeitos estabelecem simultaneamente com diferentes nações. ${ }^{22}$ Como as experiências dessas pessoas e famílias estão estreitamente ligadas a ambos os países, suas memórias são transnacionais, como poderemos perceber mais adiante.

pela primeira vez em 1972, o qual, segundo o autor, naquele momento não despertou maior interesse. Somente dez anos depois, uma nova edição do livro, com um título mais chamativo (Die Mitläuferfabrik), o livro e tema encontrou maior recepção entre a comunidade científica. NIETHAMMER, Lutz. Die Mitläuferfabrik. Die Entnazifizierung am Beispiel Bayerns. Berlin, Bonn: Verlag J. H. W. Dietz Nachf., 1982, p. V-XI. Esta e outras publicações científicas que problematizam o processo de "desnazificação", entretanto, não têm tido muita visibilidade na esfera pública em geral.

${ }^{19}$ BENZ, op. cit., p. 71.

${ }^{20}$ TAVARES, op. Cit. p. 75.

${ }^{21}$ Além destes, outros retornaram ao Brasil por conta própria e até mesmo antes de 1947, como nos comentaram alguns entrevistados, inclusive os pais e o marido da entrevistada adiante citada. Os números acima citados, portanto, não englobam todos os brasileiros e parentes alemães que voltaram da Alemanha para o Brasil após a II Guerra.

${ }^{22}$ HOERDER, Dirk. Transnational, Transregional, Transcultural: Social History and Labor Migrants' Networks in the 19th and 20th Centuries. In: UNFRIED, B.; MITTAG, J.; LINDEN, M. van der.; HIMMELSOSS, E. (Ed.). Transnationale Netzwerke im 20. Jahrhundert. Historische Erkundungen zu Ideen und Praktiken, Individuen und Organisationen. Leipzig: AVA - Akademische Verlagsanstalt, 2008. 


\section{Apontamentos sobre as entrevistas}

Vinte pessoas que voltaram para o Brasil (ou acompanharam a família) entre 1946 e 1948 foram entrevistadas pela autora, duas delas por duas vezes. ${ }^{23} \mathrm{~A}$ elas foi comunicada a utilização de pseudônimos, no caso de citação das entrevistas, como forma de deixá-las mais à vontade para falar de si e da família. Todas as entrevistas foram feitas na língua alemã. Pudemos perceber que tal procedimento facilitou a rememoração de fatos, processos ou temas muitas vezes traumáticos ou desconfortáveis, como é o caso do nazismo. Apesar de a maioria saber falar português, os mais velhos se expressam melhor em alemão por terem nascido e vivido num ambiente cultural e social alemão, seja na Alemanha ou no Brasil. O psicólogo social Harald Welzer, estudioso do funcionamento da memória, aponta para uma congruência entre as circunstâncias sociais dos fatos rememorados e a sua revocação, ${ }^{24}$ o que nos faz argumentar que a utilização da mesma língua usada durante os acontecimentos sobre os quais se narra pode ativar e facilitar sua rememoração.

Nessas ponderações, levamos em conta que a memória não é pura, mas mediada pela linguagem. Segundo Ecléa Bosi, inspirada na obra de Maurice Halbwachs, "o instrumento decisivamente socializador da memória é a linguagem". ${ }^{25}$ Durante as entrevistas foram muitas vezes utilizadas expressões em alemão que se referem a eventos, processos ou elementos da cultura e da história alemãs, os quais, se traduzidos literalmente, podem não expressar exatamente os significados da época e a elas atribuídos pelos entrevistados. ${ }^{26} \mathrm{O}$ fato de a entrevistadora ser historiadora e compartilhar de um sistema de códigos de expressão, no caso, a língua alemã, permitia o uso de algumas expressões que, do contrário, precisariam ser explicadas ao interlocutor. Isto não quer dizer que acreditamos que tais condições de entrevista tenham possibilitado narrativas orais mais "verdadeiras". Sabemos que as condições de produção das entrevistas interferem na construção de narrativas orais e, neste sentido, apontamos para alguns aspectos da sua constituição, com o intuito de pensar também a relação

\footnotetext{
${ }^{23}$ Entrevistas feitas entre 2009 e 2010 no Brasil, para o projeto de pesquisa Memórias da guerra e do nazismo: a repatriação de cidadãos brasileiros da Alemanha após a II Guerra Mundial (Programa de Estágio Pós-Doutoral CAPES).

24 WELZER, Harald. Das kommunikative Gedächtnis. Eine Theorie der Erinnerung. 2a. Ed. München: Beck, 2008, p. 37.

${ }^{25}$ BOSI, Ecléa. Memória e sociedade. Lembrança de velhos. 3. ed. São Paulo: Cia. das Letras, 1994, p. 56.

${ }^{26}$ Sobre estas questões vide meu artigo: FROTSCHER, $2011 \mathrm{~b}$.
} 
entre o narrado e o contexto da rememoração. Tais observações, a meu ver, me parecem pertinentes considerando ser a linguagem o instrumento socializador da memória e estarmos tratando de migrações internacionais entre países de línguas diferentes.

O texto a seguir é baseado em narrativas orais de dois entrevistados, Lieselotte e Fritz Wiebe ${ }^{27}$ mãe e seu filho mais velho. Sua família é um dos exemplos de múltiplas migrações entre Alemanha e Brasil, cuja força motriz foi o marido e pai, Karl, que foi membro de um grupo local do NSDAP no Brasil. Durante a Segunda Guerra Mundial e a repatriação, Lieselotte e Fritz viveram juntos e, assim, foram testemunhas de muitos eventos e situações vividas em comum. Muitos deles, contudo, foram experimentados e percebidos de maneiras diversas e, às vezes, até mesmo contraditórias. Este artigo pretende problematizar como rememoram o passado do marido e do pai, respectivamente, a partir de discussões sobre memória e história oral.

Trata-se de um estudo de caso de uma família burguesa e que, por isso, difere da posição social da maioria do conjunto dos entrevistados. Como lembra o historiador Michel Vovelle: "O estudo de caso representa o retorno necessário à experiência individual, no que ela tem de significativo, mesmo que possa parecer atípica (...)"28 Interessa-nos analisar aqui os aspectos subjetivos na construção de narrativas sobre histórias familiares. Neste sentido, como assinala Alessandro Portelli: "A impossibilidade de passar do individual ao social tornaria inutilizáveis para fins científicos as fontes orais e as memórias, na medida em que a subjetividade constitui seu próprio argumento." ${ }^{29} \mathrm{O}$ mesmo autor ainda alerta sobre "a ilusão do testemunho como uma tomada de consciência imediata, de primeira mão, autêntica, fiel à experiência histórica". ${ }^{30}$

\section{Como mãe e filho falam sobre nazismo e guerra}

Poder entrevistar Lieselotte W., uma mulher lúcida de mais de 90 anos, que vivenciou ativamente não apenas a repatriação, mas também a migração para a Alemanha, em 1938, já como mãe, constitui algo extraordinário. Essa foi a razão de termos feito duas entrevistas com ela.

\footnotetext{
${ }^{27}$ Utilizamos pseudônimos em razão dos objetivos deste artigo.

28 VOVELLE apud LEVI, Giovanni. Usos da biografia. In: AMADO, Janaína; FERREIRA, Marieta de M. (Coord.) Usos \& abusos da história oral. 5. ed. Rio de janeiro: Ed. FGV, 2002. p. 167-182.

${ }^{29}$ PORTELLI, Alessandro, op. cit., p. 61.

${ }^{30}$ PORTELLI, Op. Cit., p. 59.
} 
Outros entrevistados, mesmo os com mais de 70 anos, vivenciaram a guerra e a ida para o Brasil apenas como crianças ou adolescentes. Esse é o caso do seu filho Fritz, que nasceu no Brasil, migrou bem pequeno com a família para a Alemanha em 1938.

Lieselotte nasceu no Brasil no seio de uma família rica e cresceu num ambiente cultural alemão, assim que o português era como uma língua estrangeira. No início dos anos 30, casou-se com Karl, um imigrante alemão e ex-combatente da Primeira Guerra Mundial. Ele havia se dirigido ao Brasil no final dos anos 1920 e, em 1936, tornou-se membro do NSDAP. ${ }^{31}$

Este engajamento foi o motivo para deixarem o Brasil, às pressas, em 1938, quando aquele partido foi proibido no país. ${ }^{32}$ Lieselotte comenta sem rodeios sobre a rápida decisão do marido de voltar à Alemanha e a venda de sua bela residência: "[...] Meu marido era muito a favor dos nazistas. Então tivemos muitos problemas aqui... e [nós] estávamos somente seis anos aqui

31 Sua filiação ao NSDAP consta na lista de membros compilada pelo governo norte-americano logo após a Segunda Guerra Mundial. Fonte: NS 9/183, Arquivo Nacional, Berlim (Alemanha). Sobre o NSDAP no Brasil, vide, entre outros trabalhos: MORAES, Luis Edmundo de S. Konflikt und Anerkennung: die Orstsgruppen der NSDAP in Blumenau und in Rio de Janeiro. Berlin: MetropolVerlag, 2005; MÜLLER, Jürgen. Nationalsozialismus in Lateinamerika: die Auslandsorganisation der NSDAP in Argentinien, Brasilien, Chile und Mexiko, 1931-1945. Stuttgart: Verlag Hans-Dieter Heinz, 1997; GAUDIG, Olaf; VEIT, Peter. Der Widerschein des Nazismus: das Bild des Nationalsozialismus in der deutschsprachigen Presse Argentiniens, Brasiliens und Chiles 1932-1945. Berlin: Wissenschaftlicher Verlag Berlin, 1997; GERTZ, René. O fascismo no Sul do Brasil: germanismo, nazismo, integralismo. Porto Alegre: Mercado Aberto, 1987; MAGALHÃES, Marionilde Brepohl de. Pangermanismo e nazismo: a trajetória alemã rumo ao Brasil. Campinas: Ed. Unicamp/FAPESCP, 1998, DIETRICH, Ana Maria. Nazismo Tropical? O Partido Nazista no Brasil. São Paulo: Todas as Musas, 2012.

${ }^{32}$ Sobre a proibição do NSDAP e o início da Campanha de Nacionalização ver, além dos trabalhos citados na nota anterior, PERAZZO, Priscila F. O perigo alemão e a repressão policial no Estado Novo. São Paulo: Arquivo do Estado, 1999; FÁVERI, Marlene de. Memórias de uma (outra) guerra. Cotidiano e medo durante a Segunda Guerra em Santa Catarina. Florianópolis: UNIVALI: UFSC, 2004; CAMPOS, Cynthia Machado. A política da língua na era Vargas: proibição do falar alemão e resistências no sul do Brasil. Campinas: Ed. Unicamp, 1998; FROTSCHER,Méri. Identidades móveis: ações e discursos das elites locais na esfera pública de Blumenau (1929-1950). Blumenau/Cascavel: Edifurb/Edunioeste, 2007. 
nesta casa [quero dizer], lá, naquela casa $^{33}$ e então viajamos para a Alemanha, de mala e cuia". ${ }^{34}$

Para Karl, casado com filha de família de situação econômica privilegiada, os motivos para retornar à Alemanha foram políticos. De um lado, estava o medo da perseguição política no Brasil e, de outro, a possibilidade de desfrutar das vantagens que esperava ter na Alemanha nazista.

À Lieselotte coube seguir a decisão do marido de deixar o Brasil. Com o retorno à Alemanha, Karl procurou se esquivar da repressão do partido nazista empreendida desde o início de 1938. Em março de 1938, o governo estadual e, em abril do mesmo, o governo federal, proibiram a prática de qualquer atividade política de estrangeiros e foi regulamentada a sua expulsão, em caso de comprometimento da segurança nacional. O líder do círculo nazista do estado já havia sido preso pelas autoridades policiais, assim como outras pessoas, provocando inquietações entre demais membros do partido. Apesar desta situação, estopim para a migração, voltar para a Alemanha vinha ao encontro da posição política de Karl. Quando fala disso, neste e noutros trechos da entrevista, Lieselotte expressa seu apoio ao posicionamento político do marido, quando diz "nós éramos muito pela Alemanha" ou "nós éramos do partido".

A filiação ao partido nazista fica apenas subentendida na primeira entrevista, enquanto que na segunda, Lieselotte dá mais detalhes sobre a participação de Karl no grupo local do NSDAP. Nessa entrevista, esse fato é naturalizado da seguinte forma:

Meu marido era político e se interessava, naturalmente, pela política alemã, participou dela também, naturalmente, e era mal visto aqui. [...] Então ele era, na verdade, o chefe do partido em [nome da cidade suprimido]. Mas graças a Deus ele nunca foi daqueles que usava uniforme. Mas seus subordinados, eles tinham que usar uniforme, mas ele nunca tinha um uniforme, por sorte, mas os outros, eles todos tinham

${ }^{33}$ Ela se refere à sua residência à época, que fica defronte a casa onde hoje reside, construída pelos pais.

34 Lieselotte Wiebe [pseudônimo]. Entrevista realizada em 24.04.2009. Entrevistadora: Méri Frotscher. As citações das entrevistas foram traduzidas pela autora. 
seus uniformes marrons. Sim, ele era assim o líder do grupo local daqui. ${ }^{35}$

A participação do marido no partido nazista é vista como algo natural. Sendo político e alemão, seria, segundo ela, natural que se interessasse e participasse da "política alemã", aqui entendida como política nazista. $\mathrm{Na}$ entrevista Lieselotte também ressalta a posição de liderança do marido. A afirmação de que ele não usava uniforme, em contraste com outros partidários, cumpre a função de destacar sua posição de classe e de liderança naquele espaço social, preocupação que, aliás, perpassa a rememoração de diversos outros fatos do passado dela e da família durante a entrevista. Mas a afirmação de que ele, "por sorte", nunca usava uniforme, dialoga com outra temporalidade. Após a guerra, segundo a entrevistada, as autoridades norte-americanas instaladas na Alemanha disporiam de fotografias do grupo local do NSDAP, do qual o marido teria feito parte e o fato dele não aparecer em uniforme do partido teria facilitado sua "desnazificação".

Ao falar da participação do marido no partido nazista, Lieselotte destaca os conflitos políticos também dentro da família. Parte dos familiares era contra a filiação ao partido nazista, em razão do receio quanto a represálias do governo brasileiro. A família tinha grande influência na política regional e tinha um patrimônio a preservar.

Além de se esquivar do perigo de prisão e extradição, Karl se aproveitou da posse da cidadania alemã, da filiação ao NSDAP e do seu capital material e social para adquirir, na Alemanha sob o nazismo, uma fábrica de um judeu, que teve de vender a propriedade para poder deixar a Alemanha nazista. No desenrolar da perseguição a judeus, propriedades comerciais e industriais foram liquidadas ou colocadas sob as mãos de "arianos". A família de Lieselotte chegou na Alemanha no auge desta política de "arianização" da economia, no mesmo ano em que foi publicado decreto para a eliminação dos judeus da vida econômica alemã. Isso favoreceu a rápida inserção econômica e enriquecimento de sua família. ${ }^{36}$ Lieselotte comenta sobre isso de maneira muito ligeira: " $E$ [nós] compramos através do banco uma firma muito boa de um judeu que queria voltar... e [nós] trabalhamos e fizemos até a firma crescer, era uma firma bem grande.

${ }^{35}$ Lieselotte W., op. Cit.

${ }^{36}$ Para uma visão panorâmica sobre a política de "arianização" da economia alemã durante o nazismo, vide ALY, Götz. Hitlers Volksstaat. Raub, Rassenkrieg und nationaler Sozialismus. Bonn: Bundeszentrale für politische Bildung, 2007, p. 5466. 
Foi uma época muito boa". ${ }^{37}$ A "compra" da empresa de um judeu é rememorada sem mais comentários, sem mencionar a política de expropriação de judeus que havia forçado o proprietário a vender seu estabelecimento. $\mathrm{O}$ fato de ele ter vendido a empresa para escapar da perseguição é narrado como uma vontade, não um ato forçado ("um judeu que queria voltar"). Diferentemente daquele destino, foi o de sua família, que teria vivido uma "época muito boa". O período de crescimento dos negócios coincidiu com a fase da guerra em que a Alemanha parecia vencer a guerra.

Durante o desenrolar da guerra, contudo, o marido foi convocado pelo Exército. Ele assumiu, entretanto, o posto de oficial na retaguarda. Nesta posição, pôde prover a família de alguns pequenos luxos, enquanto a maioria da população já sofria com as consequências materiais da guerra. A "época muito boa" chegou ao fim com o bombardeio da fábrica, depois do que Lieselotte e seus filhos se mudaram para a casa de seus pais, numa cidade grande no Oeste da Alemanha. Seus pais haviam ali se instalado depois de viajarem de férias para a Alemanha, em 1939, e serem surpreendidos pela eclosão da guerra. Em 1944, Lieselotte e filhos, entretanto, novamente precisaram se mudar, em razão do perigo de bombardeio. Ela e os filhos, juntamente com outras mães e filhos, tomaram parte da Kinderlandverschickung, ação de evacuação de famílias para áreas seguras de bombardeios empreendida pelo governo. ${ }^{38}$ Lieselotte e filhos foram encaminhados para uma área rural e segura na Turíngia, Centro-Leste da Alemanha, ou uma "primitiva" propriedade de agricultores, como ela se refere. Essa experiência lhe provocou desconforto e estranhamentos em razão das diferenças dos modos de viver e habitar e, sobretudo, da reação fria daquela família, a qual desagradava o fato de ter que abrigar a esposa e filhos de um oficial.

Muito embora algumas de suas experiências na época da guerra apresentem aspectos comuns a milhões de alemães - bombardeio, evacuação, falta de comida - a forma como Lieselotte as narra é diferente da de outros entrevistados. As diferenças de classe percebidas durante a guerra são frequentemente lembradas por ela. Sua rememoração do passado é, assim, mediada também por uma forte consciência de classe.

\footnotetext{
${ }^{37}$ Lieselotte W., op. Cit.

38 A evacuação de muitas áreas ameaçadas de bombardeios foi uma medida tomada pelas autoridades nacional-socialistas desde 1943 e atingiu de 9 a 10 milhões de pessoas, sobretudo mulheres e crianças. No interior dessa ação foi procedida a Kinderlandverschickung (envio de crianças e mães com bebês para áreas seguras de bombardeio), que envolveu mais de 2 milhões de crianças.
} 
No final da guerra, a Turíngia havia sido ocupada por tropas norteamericanas, mas em razão do acordo firmado entre os Aliados durante a Conferência de Jalta, os norte-americanos acabaram deixando a região, que foi, no início de julho de 1945, ocupada pelas tropas soviéticas. Esse período é relembrado com muitos detalhes, ao passo que a capitulação alemã, em 8 de maio de 1945, sequer é citada por Lieselotte. Não somente para ela, também para muitos alemães, aquela data não foi um marco em suas memórias. ${ }^{39}$ Os momentos mais marcantes e desesperadores para Lieselotte, durante sua estadia na Alemanha, foram os que envolveram a ocupação soviética e a fuga em direção à zona norte-americana ou, como diz, "de volta à Alemanha" (grifo meu), como se a zona de ocupação soviética não fosse mais parte do país. Muito embora aquele território fosse alemão e tenha continuado a ser - mesmo que, depois de 1949, parte da República Democrática Alemã -, a forma como ela o representa revela a influência ideológica posterior da guerra fria. Um tom negativo permeia a representação dos russos, geralmente referidos no singular ("Der Russe"). Essa representação pejorativa, já propagada pelo nazismo, se reproduz também na entrevista do seu filho, como se verá mais adiante.

Embora Lieselotte afirme não recordar com precisão de alguns fatos, em razão da idade avançada, quando comenta sobre a chegada dos russos e o perigo do estupro, que de fato ocorreu com diversas moças da localidade, sua narrativa ganha detalhes, passando a descrever algumas cenas que vivenciou:

\begin{abstract}
Mas os russos [...] queriam mulheres alemãs. E então veio aquele homem e disse pra mim: 'Hoje de noite eu vir para você [sic]'. Eu, eu disse, eu gritei: 'Não, de jeito nenhum!'. 'Eu vir para você [sic] hoje de noite!'. Então, fazer o quê? A agricultora então me escondeu na casa de parentes dela, a bondosa [...]. ${ }^{40}$
\end{abstract}

Nesta situação de perigo, Lieselotte pôde contar com a solidariedade da mulher que teve de abrigá-la em sua propriedade. Ela lhe ajudou a se esconder. A mudança do relacionamento com ela, ao longo de sua estadia, é

${ }^{39}$ O historiador alemão Hans-Ulrich Wehler problematizou o ano de 1945 como marcante na história alemã, pleiteando que a cisão de 1945 seja alargada até junho de 1948, quando ocorreu a reforma monetária e o melhoramento da situação sócioeconômica na Alemanha. "Das längste Jahr. Interview mit Hans-Ulrich Wehler". Die Zeit, n. 1, Teil 2, April 2005, p. 26-30.

${ }^{40}$ Lieselotte W., op. Cit. 
ressaltada, ainda, ao lembrar de outra ajuda que havia recebido dela noutra ocasião, quando teria lhe dado dois ovos, referência que evidencia a carência de mantimentos vivenciada naquela época. A forma como Lieselotte fala sobre o o perigo de estupro lembra narrativas de mulheres alemãs analisadas por Erika M. Hoerning. Esta historiadora pôde perceber que enquanto os homens alemães entrevistados se referiam ao estupro das mulheres ao falarem de suas experiências de guerra com o inimigo, as mulheres alemãs se referiam a esse tema no contexto de suas próprias estratégias de sobrevivência. ${ }^{41}$

Em sua entrevista, Lieselotte conta como subornou guardas de fronteira russos para fugir em direção à zona norte-americana de ocupação, numa ação também descrita mais detalhadamente. $\mathrm{O}$ medo em relação aos russos e à perda dos filhos durante a fuga, - o que ocorreu a muitas famílias de refugiados e expulsos alemães - assim como as condições difíceis do transporte, são elementos marcantes dessa parte de sua história de vida.

Quando se refere a esse período, Lieselotte se refere várias vezes à "falta de relações", ou seja, de conhecidos que pudessem lhe ajudar. A expressão de um sentimento de estar abandonada à própria sorte se refere, sobretudo, aos fatos ocorridos entre final de 1944, quando ocorreu a evacuação, e meados de 1945, quando a Turíngia foi ocupada pelas tropas do Exército Vermelho. Esta ênfase denota a angústia dessa mãe acostumada com a proteção familiar e, sobretudo, com os benefícios e privilégios advindos do capital material e social da família. Estes elementos mostram também como as experiências e as memórias são construídas a partir do lugar social do entrevistado. Como esposa e membro de família da burguesia, em geral sempre houve quem se ocupasse do trabalho doméstico e quem resolvesse as dificuldades e problemas que implicassem contatos na esfera pública. E por mais que a guerra lhe tenha também trazido dificuldades, ela a vivenciou como esposa de oficial. Foi nesta posição que foi encaminhada, por ocasião da evacuação, à melhor propriedade rural da localidade. Devido também aos bens de valor que ainda possuía, pôde fugir da zona soviética, e assim por diante.

Lieselotte conseguiu voltar para a casa dos pais, onde mais tarde reencontrou o marido e permaneceu até a repatriação. Retornar ao Brasil não era sua vontade, segundo ela, pois significava uma desonra perante os

${ }^{41}$ HOERNING, Erika M. Frauen als Kriegsbeute. Der Zwei-Fronten Krieg. Beispiele aus Berlin. NIETHAMMER, Lutz; PLATO, Alexander von. (ed.). "Wir kriegen jetzt andere Zeiten". Auf der Suche nach der Erfahrung des Volkes in nachfaschistischen Ländern. Vol. 3. Berlin/Bonn: Verlag J. H. W. Dietz Nachf., 1985, p. 328. 
outros familiares: "[...] porque nós estávamos no partido [...], por isso eu já nem queria mais voltar, mas meu marido, ele conseguiu de novo". ${ }^{42}$ A decisão de migrar veio novamente do marido, o qual pôde voltar ao Brasil por meio do processo de "repatriação" da Missão Militar Brasileira, se utilizando do fato de a esposa e parte dos filhos terem nascido no Brasil. Para Karl, deixar a Alemanha significava não apenas fugir da fome e das ruínas, mas também deixar para trás parte do passado. Também era uma oportunidade de começar de novo, se reinserir socioeconomicamente num ambiente que já conhecia.

Também os pais de Lieselotte, ambos descendentes de alemães nascidos no Brasil e, assim, reconhecidos como cidadãos brasileiros, souberam negociar suas identidades nacionais e, por meio disso, preservar sua propriedade na Alemanha. No imediato pós-guerra, seu pai realçou sua origem brasileira às autoridades Aliadas para evitar o mesmo tratamento dado aos alemães:

Eles tinham uma placa na frente da entrada da casa: "Casa Brasileira" [...] Diversas vezes foi dito a eles que eles deveriam deixar a casa [...] "Sim, mas nós somos brasileiros, nós não vamos sair daqui" [eles diziam], e então também ficaram com a casa. ${ }^{43}$

Os pais voltaram depois da guerra ao Brasil de avião, partindo da Suíça. Não constam, portanto, como provavelmente outras pessoas, das estatísticas da Missão Militar Brasileira. Lieselotte, acompanhada dos filhos, embarcou no navio Santarém no reveillon de 1946, ou seja, na primeira leva de repatriados. Ironicamente, tratava-se de um antigo navio alemão recebido pelo Brasil como reparação depois da Primeira Guerra Mundial. A resignação em ter que voltar para o Brasil é reforçada pelo fato de ter que viajar, pelo menos no início da viagem, na terceira classe. É já no navio, entretanto, o reconhecimento do capital social de sua família the permite ser remanejada para a primeira classe, após ser apresentada ao capitão, como ela narra com satisfação.

O marido não pôde acompanhar a família, pois como era cidadão alemão, ainda devia esperar a autorização para deixar o país, o que dependia do resultado do processo de "desnazificação". Entretanto, logo depois foi liberado, de forma que conseguiu chegar no Brasil, de avião, até mesmo antes da esposa e dos filhos. Exatamente ele, que foi o motor da ida à Alemanha, partidário do NSDAP e aproveitador do regime, chegou no

\footnotetext{
${ }^{42}$ Lieselotte W., op. Cit.

${ }^{43}$ Lieselotte W., op. Cit.
} 
Brasil antes do que outros "repatriados", que não tinham sido membros daquele partido.

De volta, Lieselotte teve que se arranjar com a vergonha e a falta de interesse dos familiares que haviam ficado no Brasil em suas experiências vividas na Alemanha:

[...] eu percebi que eles nem tinham interesse pelo que a gente passou na Alemanha. Tudo o que eles passaram aqui era mais importante - eles também estavam na cadeia, etc [...] [esclarece que conhecidos foram mantidos por bastante tempo na prisão durante a repressão ao nazismo]. Isso foi um exagero, o que eles fizeram aqui. $\mathrm{O}$ governo... Mas isso era mais importante para eles do que o que nós passamos na Alemanha. E, então, a gente fica quieto, permanece quieto. ${ }^{44}$

A repressão aos alemães no Brasil durante a guerra é interpretada como uma medida exagerada do governo brasileiro e o envolvimento de sua família com o nacional-socialismo não são avaliados com criticidade, muito embora admita que isto tenha causado problemas para si e sua família.

Os fatos vividos e rememorados por Lieselotte permitem analisar a relação entre política e sentimentos/ressentimentos. Parte da família que ficou no Brasil teria sido abalada por conta da repressão e da intervenção do governo brasileiro na empresa que possuíam. Lieselotte se ressentia, após o retorno, dos ataques da família a seu apoio à atuação política do marido em prol do nacional-socialismo no Brasil, o que impedia que compartilhasse o que viveu e sofreu durante a guerra na Alemanha. Nove anos vividos na Alemanha fizeram com que ela, ao voltar, mesmo que para a mesma cidade e família, adentrasse numa configuração social e numa memória coletiva transformada pelos recentes acontecimentos.

Já idosa, muitos anos depois da guerra, Lieselotte escreveu duas memórias, uma sobre a evacuação da família para a Turíngia, ocorrida em outubro de 1944, cobrindo eventos até setembro de 1945 e outra sobre as vivências num campo de deslocados de guerra, enquanto aguardavam a repatriação. A escolha dos eventos demonstra o caráter extraordinário em sua história de vida e, também, tem a ver com os destinatários daquelas memórias, seus descendentes. Ambos os textos rememoram menos de três anos da vida de Lieselotte, exatamente os de maiores dificuldades e

${ }^{44}$ Lieselotte W., op. Cit. 
provavelmente os mais marcantes, os quais não puderam ser francamente compartilhados com parte da família após o retorno ao Brasil, nem expressos na esfera pública. Estas memórias autobiográficas também são memórias da família, escritas para serem guardadas para as gerações seguintes. A psicóloga social Ecléa Bosi reflete sobre a função social das pessoas idosas na sociedade em que vivemos, a saber, a de ser a memória da família, do grupo e da sociedade. ${ }^{45}$ Eles teriam uma memória social atual mais contextualizada e definida, pois são expectadores de um quadro já finalizado e bem delineado no tempo. ${ }^{46}$

No caso de Lieselotte, as memórias da família foram redigidas sob incentivo do filho Fritz, o qual, inclusive, fez inserir no primeiro texto fotografias da localidade da evacuação, tiradas em 1989, após a queda do muro, quando visitou aqueles lugares. Tais memórias autobiográficas, práticas de "arquivamento do eu", cumprem, portanto, o papel de produção de significados tanto na construção de si mesmo, como na fixação de uma memória para a família. Talvez o incentivo para que a mãe escrevesse suas memórias, tivesse a ver com uma vontade de registrar e, assim, fixar a memória da família. A repressão ao nazismo no Brasil construiu uma memória que maculou a imagem pública de muitos alemães membros do partido nazista, então vistos como "inimigos da Nação". A construção das memórias autobiográficas de Lieselotte se relaciona também com tais fatos. Suas memórias são, ainda, expressão do discurso dos alemães como vítimas da guerra.

O filho, em sua entrevista, constrói suas memórias a partir do seu lugar social de homem público e empresário. No momento da entrevista, ainda trabalhava ativamente no cargo de empresário. Ao falar sobre seu passado e o da família, Fritz procura a todo o momento se auto-representar como homem bem sucedido, construindo uma imagem de si para si e também para a entrevistadora. Depois da conversa, ficou a sensação de ter filtrado muito mais que a mãe as lembranças do passado e de tê-lo enquadrado de forma a construir uma história de vida conveniente à sua imagem de homem de elite e de projeção pública. Sua condição de classe foi expressa em diversos momentos da entrevista.

No início da entrevista, percebe-se que as razões dadas para a migração da família para a Alemanha, em 1938, diferem das apresentadas pela mãe:

${ }^{45}$ Ecléa Bosi, op. cit., p. 63.

${ }^{46}$ Idem, p. 60-63. 
Então veio em [19]38 a lei de Getulio Vargas que proibiu a língua alemã em [nome da cidade suprimido]. Isto não foi, na verdade, previsto pelo governo federal do Brasil, isso foi mais um problema de razões políticas, de razões político-partidárias, que foi agido de forma tão rígida, que cada pessoa que falasse alemão fosse presa e até internada [nos então chamados campos de concentração] e pelo menos fosse considerado um inimigo do país. E então o meu pai decidiu que nós voltaríamos, que ele voltaria com a família para a Alemanha e nós então emigramos, vendemos tudo aqui e fomos para a Alemanha. ${ }^{47}$

Segundo Tzvetan Todorov, não há lembranças mais verdadeiras que outras. Para ele, todas as lembranças são irrefutáveis, "valem por sua própria existência, e não pela realidade à qual remetem". ${ }^{48}$ No caso da família Wiebe, interessante perceber que embora mãe e filho narrem sobre os mesmos fatos, enquanto a mãe fala que o motivo para migrar para a Alemanha foi o envolvimento do marido no partido nazista, o filho silencia a esse respeito e, ao invés da menção ao partido nazista, se refere à repressão à língua alemã.

A narração desse período de sua vida não se baseia exatamente em suas próprias experiências, como Fritz mesmo diz na entrevista - em 1938 ele era ainda uma criança pequena -, mas em informações obtidas mais tarde. Entretanto, não se tratam apenas de acontecimentos "vividos por tabela", ${ }^{49}$ socializados na família ou entre pessoas próximas, mas de uma narrativa que procura silenciar detalhes do passado político do pai. Em sua narrativa sobre a história familiar são embutidos elementos que dizem respeito à repressão de alemães e descendentes durante a Campanha de Nacionalização que havia iniciado meses antes de sua família se dirigir à Alemanha. Memórias dessa Campanha foram compartilhadas por testemunhas e parentes no Brasil e ganharam maior visibilidade, nos últimos anos, por meio de livros, matérias jornalísticas, reportagens para a TV e filmes documentários.

${ }^{47}$ Fritz Wiebe [pseudônimo]. Entrevista realizada em 10.07.2009. Entrevistadora: Méri Frotscher.

${ }^{48}$ TODOROV, Tzvetan. Memória do mal, tentação do bem. Indagações sobre o século XX. Tradução Joana Angélica D'Ávila. São Paulo: Arx, 2002, p. 151.

49 POLLAK, Michel. Memória e identidade social. Estudos Históricos, Rio de Janeiro, v. 5, n. 10, 1992, p. 200-212. 
$\mathrm{O}$ ato de agregar elementos de outras fontes nas memórias autobiográficas, como mostra o psicólogo social Harald Welzer e sua equipe no livro Opa war kein Nazi [Vovô não era nazista], evidencia o caráter comunicativo e associativo da memória. ${ }^{50}$ Este autor se pauta no conceito de "memória comunicativa" desenvolvido por Jan Assmann, para fundamentar a tese de que ideias e imagens do passado são compostas no cotidiano a partir de diferentes fontes, como conversas na família, escola e mídia. ${ }^{51}$ Suas reflexões apontam para a interdependência entre memória e sociedade, demonstrando que os significados atribuídos a informações não se constituem através de um processo meramente neuronal ou individual, mas através da comunicação. ${ }^{52}$ Em nosso caso, experiências do passado vividas por parentes e conhecidos, como a repressão à língua alemã e prisões, e que pareceram oportunos de serem referidos numa entrevista, foram incorporados na construção das memórias de Fritz, ao falar do seu pai, que justamente com o retorno à Alemanha pretendeu escapar daquela repressão. Foi exatamente a atuação de membros do partido nazista no Brasil, como o seu pai, que constituiu um dos principais argumentos para a repressão generalizada de alemães e seus descendentes.

Somente noutro momento da entrevista, ao ser diretamente perguntado sobre os conflitos políticos envolvendo o pai no Brasil, que Fritz se refere ao envolvimento dele com o nazismo. Ao invés de falar de sua posição de liderança no grupo local do partido, como o fez a mãe, Fritz se refere à forte influência da "ideologia nazista" sobre o pai, minimizando assim seu papel ativo:

Entrevistadora: O seu pai foi também para a Alemanha por causa dos conflitos políticos aqui?

Fritz: Sim, também. Ele era, digamos, aqui, ele ainda era influenciado pela ideologia nazista, fortemente influenciado e quando ele retornou para a Alemanha, ele então percebeu que era um partido mau, eram tudo pessoas pequenas que de repente ganharam o poder, mas que não tinham caráter. Então ele brigou

\footnotetext{
${ }^{50}$ WELZER, op. cit., 2008.

${ }^{51}$ WELZER, Harald; MOLLER, Sabine; TSCHUGGNALL, Karoline. Opa war kein Nazi. Nationalsozialismus und Holocaust im Familiengedächtnis. 6a. Ed. Frankfurt am Main: Fischer Taschenbuch Verlag, 2008, p.7-17. Deste livro há uma versão em espanhol, intitulada Mi abuelo no era nazi, publicada em Buenos Aires pela Prometeo Libros, 2012.

52 Esta é a principal tese do autor, daí intitular seu livro Das kommunikative
} Gedächtnis (A memória comunicativa). Harald Welzer, op. cit., p. 10. 
terrivelmente com eles lá... Eles então expulsaram ele do partido e a única possibilidade de escapar do campo de concentração era servir no Exército. E por isso ele também pôde permanecer lá e voltar de novo depois para o Brasil, pois ele pôde provar que ele foi expulso do partido, pois ele se pegou com os funcionários do partido que se aproveitavam de sua função. E ele já era industrial na época e não deixou que esses caras mandassem nele. ${ }^{53}$

Como o envolvimento do pai com o nazismo não era possível de ser silenciado, diante do conhecimento e das intervenções da autora durante a entrevista, - muito embora esse envolvimento seja representado como passivo ("era influenciado pela ideologia nazista") - o pai é transformado quase numa vítima dos nazistas: "eles então expulsaram ele do partido e a única possibilidade de escapar do campo de concentração era servir no Exército". A narração da suposta frustração do pai em relação ao NSDAP na Alemanha, um "partido mau", de "pessoas pequenas [...] que não tinham caráter", é mediada pela afirmação de uma consciência de pertencimento à outra classe. Esse diferencial teria supostamente feito o pai romper com os nazistas. Ao invés do beneficiamento da família por meio das medidas de "arianização" da economia alemã, em sua entrevista aparecem como beneficiados os funcionários do partido, que ao subirem ao poder "se aproveitaram de sua função". ${ }^{54}$ A estória da expulsão do partido serve de atestado moral para o pai.

A partir deste fato, o pai Karl Wiebe tornou-se oficial do Exército. Isso é tomado, inclusive, como um dos elementos explicativos para o fato de o pai ter obtido autorização das autoridades militares aliadas para deixar a Alemanha após a guerra: “[...] como nós não tínhamos antecedentes nazistas e como meu pai foi oficial, isso de qualquer maneira não era problema". ${ }^{55}$ Nesse momento inicial da entrevista, há a negação do envolvimento com o nazismo. Mais adiante, houve uma mudança na forma de narrar o assunto, em razão das perguntas da entrevistadora, como vimos. Não é mais o fato de

\footnotetext{
${ }^{53}$ Fritz Wiebe, op. cit.

${ }^{54}$ Götz Aly argumenta que o Estado nazista se manteve porque o povo alemão também se beneficiou das injustiças do nacional-socialismo (roubo e guerra racial, expressões usadas no subtítulo de seu livro). ALY, Op. cit.

55 Idem. Os pré-requisitos para a saída da Alemanha, por meio da ação de "repatriação", eram outros. Sobre isso ver FROTSCHER, (2013a).
} 
Karl ter sido oficial, mas a estória da sua saída do NSDAP que é usada para explicar a autorização das forças aliadas para deixar o país.

$\mathrm{O}$ fato do ex-major Karl Wiebe ter passado pelo processo de “desnazificação" pelas autoridades aliadas, e de ter, depois disso, obtido autorização para migrar, lhe fez eximir o pai de qualquer comprometimento maior com o partido nazista. A composição de uma memória confortável sobre o pai tem uma relação com a pecha de nazista associada a ele desde que havia deixado o Brasil. Assim, na reconstituição do passado feita pelo filho, seu pai, ao invés de um membro destacado do grupo local do NSDAP, aparece como um resistente às ações daqueles partidários na Alemanha. Em suas memórias, o pai teria, inclusive, advertido o filho para não se matricular, quando tinha 12 anos, numa NAPOLA (Nationalpolitische Lehranstalt), como se chamavam as escolas de elite nacional-socialistas.

Não é o desconhecimento da história o motivo para fatos não serem mencionados ou serem encadeados em conexões convenientes. $\mathrm{O}$ entrevistado conhece discussões em torno da história do nacionalsocialismo, em razão de seus contatos intensos na Alemanha e de ter ali estudado e, inclusive, pesquisas sobre o nacional-socialismo no Brasil. O psicólogo social Harald Welzer e seus colegas, ao lidar com a problemática de como as pessoas compõem ideias e imagens sobre o passado nacionalsocialista, mostram como a consciência histórica tem uma dimensão cognitiva e uma emocional. Por conta disso é possível, e mesmo comum, haver uma disparidade entre o conhecimento histórico (adquirido através dos livros, da escola, etc) e as memórias familiares. O seu livro Opa war kein Nazi [Avô não era nazi], baseado em entrevistas com testemunhas, filhos e netos, demonstra como a maioria dos entrevistados partiu do pressuposto de que os familiares não foram nazistas e de que não existiram antisemitas e criminosos de guerra em suas famílias. Os autores constataram, por meio da pesquisa, um paradoxo: quanto mais instruídas as pessoas, menos consideram que parentes estiveram envolvidos com o nazismo. ${ }^{56}$

Assim como os autores, constatamos que estórias de pessoas que viveram sob o nacional-socialismo podem ser totalmente reinterpretadas pelas gerações seguintes. Lieselotte não expressa desconforto em relação às consequências do nazismo. Muito embora admita a participação do marido no partido e a sua na NS-Frauenschaft (organização para as mulheres do NSDAP), não manifesta qualquer avaliação crítica sobre esse passado. Fritz muito menos, já que ou silencia inicialmente o envolvimento político do pai

${ }^{56}$ WELZER; MOLLER; TSCHUGGNALL, op. Cit., 2008. 
ou, depois, o transforma quase num resistente. Enquanto Lieselotte fala sem rodeios da participação política do marido, o filho o preserva, de forma a tornar a memória do pai mais confortável.

A interpretação do passado pessoal e familiar, presente na entrevista de Fritz, é mediada, pelo menos em parte, pela sua condição de classe, pelo seu posicionamento liberal e pela sua posição na esfera pública. A educação disciplinada, recebida sob o nazismo, e as dificuldades vividas durante a guerra teriam sido até mesmo positivas, segundo Fritz, que afirma que tais fatos teriam sido positivos para seu desempenho profissional futuro. Ele havia sido submetido à educação nazista não apenas na escola, mas também na organização para a juventude do NSDAP. Mesmo antes de completar 10 anos, apresentou-se para participar da Deutsches Jungvolk (Juventude Nazista Alemã), que antecedia a entrada na Hitlerjugend (Juventude Hitlerista). Ao mesmo tempo em que minimiza a atuação do pai enquanto membro do partido nazista, valoriza, em sua entrevista, elementos da educação nazista, falando da empolgação que tinha, então, em participar daquela organização:

[...] quando crianças, nós queríamos entrar na Juventude Hitlerista, isso era o máximo para nós. Mas só se podia entrar na Juventude Hitlerista com 14 anos. E eu só tinha 9 e com 10 podia-se tornar um Pimpf, isto é, entrar para a Juventude Nazista Alemã, eles tinham também um uniforme, mas não eram tão rígidos como a Juventude Hitlerista. Então, com 9 anos eu já me apresentei como voluntário para me tornar um Pimpf. Então eu pude usar uniforme, até hoje eu gosto do militar [...] se tinha que ser cumprimentado com "Senhor" e não se era mais castigado. E se eu hoje penso o que foi o mais importante da minha educação, foi essa disciplina, com disciplina se consegue tudo..$^{57}$

Se a juventude nacional-socialista, assim como o partido em geral, era uma instância na qual se falava de uma Volksgemeinschaft (comunidade étnica e racial alemã) e de fraternidade sem distinção de classes; chama a atenção o fato de Fritz valorizar a hierarquia social, e expressar a satisfação em ter sido tratado de maneira diferenciada em sala de aula por integrar a Juventude Alemã. A educação e a participação na juventude nazista permanecem sem problematização, seus sentidos e consequências não são discutidos. Ao contrário, a disciplina é representada como um dos fatores para seu sucesso profissional, sem que se leve em conta outros fatores

${ }^{57}$ Fritz Wiebe, op. cit. 
importantes, em seu caso, como a posse de capital material, social e cultural da família. A valorização da disciplina sob o regime nazista é tomada, na continuação da entrevista, inclusive como elemento para se julgar negativamente o suposto comportamento indisciplinado de parte da população brasileira atual.

Se a mãe se refere frequentemente às privações e dificuldades da época da evacuação, o filho pouco as menciona e quando o faz, acrescenta de que elas foram ligeiramente superadas. As situações extremas, lembradas de forma dramática pela mãe, são lembradas a partir de suas vivências enquanto crianças, enquanto aventura ou "acontecimento fantástico", forma como ele apreendeu, à época, a guerra:

Para as crianças a guerra é um acontecimento fantástico, é magnífico ir de noite, no escuro, no bunker ou então no porão [...] com toda a família junto, ficar sentado e esperar enquanto que lá em cima as bombas caem. É uma coisa fantástica. No dia seguinte então saímos para colher estilhaços de granada. A gente nem podia tocá-las, de tão quentes que elas ainda estavam [...] ali vimos mortos na rua, isso tudo era pra nós uma coisa fantástica. ${ }^{58}$

Segundo Beatriz Sarlo, toda narração do passado é uma representação, ou seja, "algo dito no lugar de um fato". A reconstituição da memória é mediada pelo envolvimento subjetivo, pelo interesse vivido em termos pessoais. ${ }^{59} \mathrm{~A}$ autora problematiza o termo "pós-memória" utilizado por alguns autores para se referir à "lembrança" de acontecimentos não vividos pessoalmente, em especial a memória da segunda geração, e argumenta que toda reconstrução do passado (e não somente a "pósmemória") é vicária e intermediada. ${ }^{60}$

É por conta da subjetividade que a evacuação, descrita pela mãe com tantos detalhes por causa do desafio de se virar sozinha com os filhos, em condições excepcionais, sequer é rememorada pelo filho em sua entrevista, a não ser mais tarde, quando perguntado:

Sim, disso eu me esqueci completamente, nós ainda fomos evacuados. Isso foi tudo fantástico pra mim.

58 Idem.

59 SARLO, Beatriz. Tempo passado. Cultura da memória e guinada subjetiva. São Paulo: Companhia das Letras, 2007, p. 93-94.

${ }^{60}$ Idem, p. 90-113. 
Para uma criança isso é uma coisa fabulosa. Nós nem refletíamos sobre o que significava largar tudo, isso era, para nós, fantástico, nenhum problema. [...] Pra minha mãe, naturalmente, isso tudo foi bem diferente, pra ela isso era catastrofal, ela tinha a total responsabilidade, sozinha, sem marido, nossa, ela foi forte ali. Incrível, incrível. Ela sempre tomou as decisões certas, nós não tínhamos nada com aquilo, eu já tinha naquela época 13 anos, quando nós voltamos de novo, da evacuação, mas mesmo com 13 é sempre a mãe que ainda decide. ${ }^{61}$

Segundo Lieselotte, durante o último ano da guerra, quando foram evacuados e o marido ainda estava ausente, sua relação como filho se tornou muito próxima: "Eu fui evacuada [...] e a única pessoa da família que eu conhecia era o [Fritz], com ele eu então falava tudo, o que eu vivenciei e na guerra, todas essas coisas". ${ }^{2}$ Seu filho hoje a orienta em muitos assuntos, como foi o caso da redação de suas memórias, como ela afirma. Entretanto, apesar de terem vivido tantas coisas juntos e da acessibilidade às memórias escritas pela mãe, o filho não narra da mesma forma as experiências deste período.

Tais questões nos colocam diante do problema da reconstrução do passado na história. No caso dos estudos sobre memória baseados em fontes orais, a reconstituição do passado é mediada de diversas formas, através de diferentes fontes e relações de naturezas distintas, como a relação indivíduo/sociedade, presente/passado, entrevistado/entrevistador, entre outras razões. No caso de mãe e filho entrevistados, o lugar de onde falam hoje, seu papel dele na esfera pública, a idade e as poucas expectativas de vida (no caso da mãe), os papéis de gênero, as memórias coletivas existentes e com as quais procuram conformar suas memórias, são alguns dos aspectos que mediaram a construção das narrativas. Parece óbvio que as lembranças de pessoas que presenciaram um mesmo acontecimento, mesmo de uma mesma família, nunca são idênticas. A questão é indagar o porquê, como estas lembranças se distinguem e quais os sentidos dados ao passado. Segundo Maurice Halbwachs, as pessoas fazem parte de distintos grupos e mesmo uma única pessoa, ao longo da vida, pode não participar dos mesmos grupos e exatamente estes relacionamentos em sociedade as fazem continuamente retocar seu passado, pois a memória se enriquece com as

\footnotetext{
${ }^{61}$ Fritz Wiebe, op. cit.

${ }^{62}$ Lieselotte Wiebe, op.cit.
} 
contribuições de fora. ${ }^{63}$ Mesmo que hajam elementos de lembrança em comum entre mãe e filho, e que dizem também respeito a uma memória coletiva compartilhada por pessoas que viveram a guerra na Alemanha, a memória pessoal é um ponto de vista da memória coletiva. ${ }^{64}$

Em que pese as diferenças, algumas representações do passado de Lieselotte e Fritz são parecidas também em relação às de outros alemães que vivenciaram a Segunda Guerra Mundial. Ambos concebem negativamente os soldados do Exército Vermelho que chegaram à localidade onde moravam na Turíngia. A representação dos russos é mediada não apenas pelo anticomunismo, mas também por formulações raciais propagadas à época do nazismo. Entretanto, se a mãe os associa principalmente ao perigo do estupro, o filho os representa a partir de sua aparência e comportamento. Os representa como sujos, decaídos e primitivos. O contraponto são os norte-americanos, representados com admiração:

E então eles [os russos] também vieram, isso era uma diferença. Os norte-americanos com jeeps chiques e os russos com carroças, cavalinhos bem pequenos na frente e carroças de quatro rodas estranhas atrás, ali eles estavam sentados em cima, todos sujos, fedorentos, bêbados, era horrível, era horrível. Era uma grande diferença. Mas também isso a gente sobreviveu. ${ }^{65}$

Estórias semelhantes sobre as impressões positivas de soldados norte-americanos são narradas em estudos sobre memórias de guerra na Alemanha e também sobre memórias de alemães que migraram para a América do Norte após a Segunda Guerra Mundial. Como na entrevista de Fritz, estas impressões negativas, frequentemente, eram reforçadas por meio da menção à imagem negativa dos "russos". ${ }^{66}$

Ao invés de traçar aproximações e distanciamentos possíveis entre as memórias dos entrevistados que vivenciaram a guerra e o nazismo - algo possível, mas que extrapola os limites deste artigo - nosso intento foi aqui iluminar interpretações do passado vivido por pessoas de duas gerações de

${ }^{63}$ HALBWACHS, Maurice. Memória Coletiva. São Paulo: Vértice, 1990, p.94-98.

${ }^{64}$ Idem.

${ }^{65}$ Fritz Wiebe, op. cit.

${ }^{66}$ FREUND, Alexander. Aufbrïche nach dem Zusammenbruch. Die Deutsche Nordamerika-auswanderung nach dem Zweiten Weltkrieg. Göttingen: V\&R unipress, 2004 (Coleção Studien zur historischen Migrationsforschung, vol. 12), p. 99. 
uma mesma família. As narrativas sobre a participação do marido e pai, respectivamente, no partido nazista são diferentes e, principalmente, um problema para o filho, que ou procura silenciar e negar tal fato ou, então, narrar eventos do seu passado de forma a preservar o pai. Pudemos perceber como a reconstituição de eventos do passado se modificam no interior de uma mesma família.

As experiências e memórias de ambos entrevistados lançam questões importantes e que dizem respeito à assim chamada Vergangenheitsbewältigung, termo conhecido no universo cultural alemão e que se refere às diversas formas de se lidar politicamente com o passado nacional-socialista e com as consequências catastróficas do nazismo depois da II Guerra Mundial. ${ }^{67}$ Se e como alemães que migraram para o Brasil e cidadãos brasileiros "repatriados" após a guerra - como foi nosso caso lidaram com isso é uma problemática relevante e que pode ser problematizada por meio entrevistas de história de vida, como as aqui discutidas. Neste aspecto contribui a História Oral, ao possibilitar discutir, por meio da produção e interpretação de histórias de vida, as diferentes formas pelas quais pessoas experenciaram o passado, como o transmitem e modificam ao longo do tempo e, também, de geração em geração.

Recebido em novembro de 2015.

Aprovado em dezembro de 2015.

${ }^{67}$ WEBER, Jürgen. Vergangenheitsbewältigung. In: BENZ, op. cit., p. 196. 